\title{
Vocal fold superficial layer of lamina propria histology after the position of mucosa pediculated flap: canine experimental study
}

\section{David Greco Varela ${ }^{1}$, Marcos Grellet ${ }^{2}$}

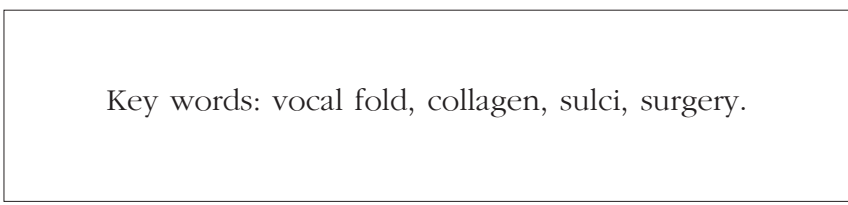

\section{Summary}

M any techniques were applied to treat patients with sulcus vocalis and scarred vocal folds. Their results were not good enough. In the Technique of Vocal Fold Pediculated Mucosa Flap, an anterior pediculated flap of vocal fold is positioned on the superficial layer of the lamina propria, below the free margin. Aim: To describe histological postoperative findings on the superficial layer of lamina propria during the application of the technique Vocal Fold Pediculated Mucosa Flap. The following parameters were compared between tested and control groups: total, type I and type III collagen and number of cellular nucleus. Study design: experimental. Material and Method: Fifteen dogs were used. One vocal fold was submitted to the intervention and the other was left as control. Each group of three dogs was sacrificed on 10, 30, 90,180 and 360 days after the experimental surgery. Hematoxylin and eosin (H.E.) and Syrius Red were the staining techniques used. Results: Type I and total collagen suggested increased results in the tested group on postoperative days 90 and 180, nevertheless there was statistical significance only on postoperative day $180(\mathrm{p}<0.05)$. Type III collagen group area was less significant than the control group on postoperative day $180(\mathrm{p}<0.05)$. The number of cellular nucleus was increased on the 10th postoperative day, but decreased after the 30th day. Discussion: The findings about total and type I collagen and the amount of cellular nucleus on the superficial layer of lamina propria were similar to laryngeal postoperative studies in dogs. More complex studies would contribute with new data about the present subject.

${ }^{1}$ Master in Otorhinolaryngology, Residence Hospital Santa Izabel.

${ }^{2}$ Ph.D., Associate Professor, Department of Ophthalmology and Otorhinolaryngology and Head and Neck Surgery, Medical School, Ribeirão Preto - USP. Department of Ophthalmology, Otorhinolaryngology and Head and Neck Surgery, Medical School, Ribeirão Preto - USP.

Address correspondence to: David Greco Varela - Rua Magno Valente 110 ap. 102B Pituba 41810-620 Salvador BA. Article submited on March 11, 2005. Article accepted on May 24, 2005. 


\section{INTRODUCTION}

The lamina propria has a key role in viscosity, contractility and formation of vocal fold mucosa wave. Its good functioning is determinant for the onset and maintenance of sustained vibration in Bernoulli's phenomenon ${ }^{1}$.

Extracellular matrix of lamina propria superficial layer comprises protein fibers and interstitial fibers ${ }^{2}$. In humans, protein fibers are distributed parallel to the free margin. Among them, collagen fibers are responsible for maintaining the local architecture, osmotic regulation and viscosity ${ }^{3}$. Type I collagen fibers are larger, better visualized and more rigid. Type III fibers are thinner, flexible and detected in initial scarring processes ${ }^{4}$.

Among the organic causes of incomplete glottic closure, vocal sulci and scarring lesions ${ }^{5}$ comprise the group of affections that require a special approach ${ }^{6,7}$. The composition of lamina propria suffers many pathological affections, whose solution has not been fully understood by Otorhinolaryngologists yet.

Surgical techniques using implants such as fat implants 8,9 , intact or solubilized temporalis fascia implant ${ }^{10}$, autologous collagen ${ }^{11,12}$ and hyaluronic acid were tested but the results obtained to present have not been universally accepted. Pontes et al. ${ }^{13}$ managed to reconstitute the subepithelial area using a stripping mucosa technique, which does not require the use of grafts or implants.

Gray et al., in 2003, perceived a new era in Laryngology when they developed studies with pluripotent cells for extracellular matrix recomposition, however, it is an option still in development and of high cost ${ }^{14,15}$.

Grellet $^{16}$ proposed a new surgical technique to approach vocal sulci. It consists of rotation of mucosa pediculated flap on the superior surface of the vocal mucosa, positioned under the surface of the detached subepithelial region, close to the free margin. It is an alternative technique that tries to improve glottic closure and reconstitution of mucosa wave.

\section{OBJECTIVES}

To describe histological findings of lamina propria superficial layer of dogs when applying a vocal fold mucosa pediculated flap, seen on days 10, 30, 90, 180 and 360 after the surgical intervention. To check chronological affections that occurred in each period of observation in the tested groups compared to the control group, analyzing levels of the following elements: total collagen, type I and type III collagen and cell nuclei.

\section{MATERIAL AND METHOD}

We conducted an experimental study in dogs that was evaluated and approved by the Ethics Committee on
Animal Studies, Campus USP - Ribeirão Preto (Protocol 03.1.324.53.6).

We selected 15 healthy adult dogs weighing on average 12 to $17 \mathrm{Kg}$ who did not have laryngeal lesions upon inspection under surgical microscope and contact laryngoscopy (Hamou I, Karl Storz 26156B). They were all animals from the Animal Laboratory, Medical School, Ribeirão Preto - USP. Surgical interventions were performed between April 2002 and May 2003. The right vocal fold was taken as the tested one and the left vocal fold was used as control in all dogs.

The studied dogs were submitted to venous general anesthesia, orotracheal intubation and ventilation by assisted pressure. Anesthetic induction was made with $50 \mathrm{mg} / \mathrm{kg}$ ketamine, associated with $1 \mathrm{ml}$ xylazin. After intubation, anesthesia was maintained with sodium thiopental $40 \mathrm{mg} / \mathrm{kg}$. Pressure ventilation was determined by device Takaoka (K. TAKAOKA, model 850-10) with 15 -sec cycles. We performed antibiotic prophylaxis with Kefazol, 30 to $40 \mathrm{mg} / \mathrm{kg}$.

For the surgical intervention, we used: straight and $90^{\circ}$ angle micro-knives, micro-scissors, curved and straight micro-detachers, and aspirators (Karl Storz, Tuttlingen, 1999). The microscope used was M-900 (DF Vasconcellos, Sao Paulo) with $400 \mathrm{~mm}$ lenses, MC-A400. The technique consisted of making a vocal fold mucosa pediculated flap with anterior irrigation $(2 \mathrm{~cm} \times 0.2 \mathrm{~cm})$ and positioning it on lamina propria superficial layer, on the region of the free margin (Figures 1, 2 and 3).

At the end of the surgery, we positioned: 1) mucosa superior surface of the pediculated flap in contact with the inferior surface of the subepithelial region, close to the free margin, and 2) inferior surface of pediculated flap in contact with the surface of the detached bed of the lamina propria.

In the first 72 hours after the surgery, we prescribed liquid diet to try to help vocal rest and scarring. Dogs were sacrificed on days 10, 30, 90, 180 and 360 after the surgery, so as to assess the behavior of the pediculated flap and scarring process of the lamina propria superficial layer at short and long term. We used an overdosage of intravenous sodium thiopental followed by $10 \mathrm{ml}$ of potassium chloride at $19.1 \%$ for the sacrifice. To collect the vocal folds, we made a medial cervical longitudinal incision with exposure of larynx through laryngofissure.

Vocal folds were soaked in paraffin in the longest axis direction and then transversal sections were made between the anterior and medium thirds of the extension. Staining substance Syrius Red ${ }^{17}$ was used to analyze total, type I and type III collagen under polarized light. Hematoxylin and Eosin aimed at identifying the cell nuclei.

Laminae were analyzed through optical microscope Olympus BX50 (Olympus Corporation, Ishikawa, Japan), and 


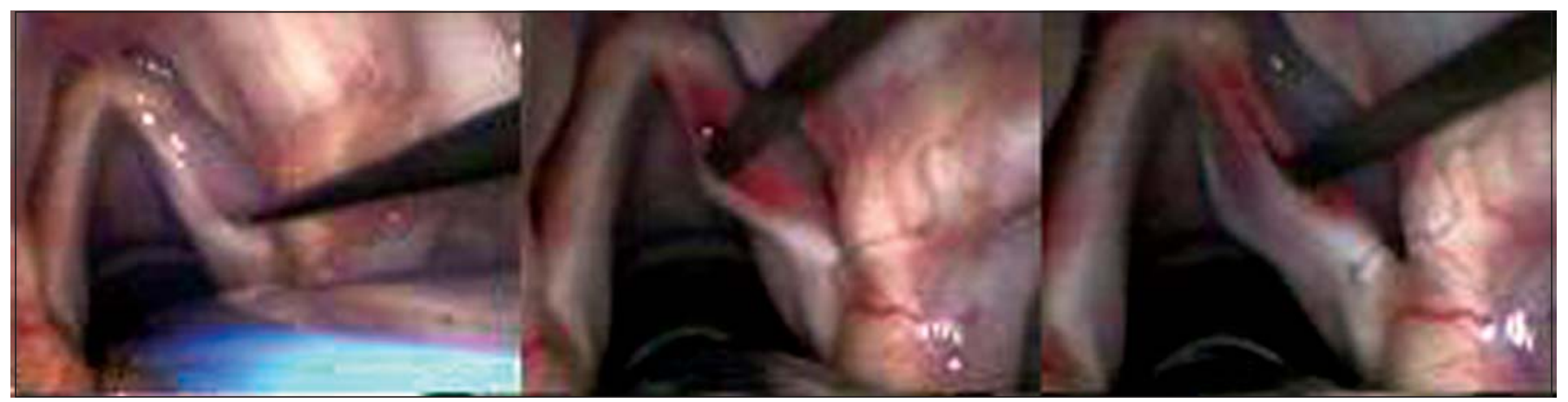

Figure 1. Incision made on the upper surface of the vocal fold and subepithelial detachment.

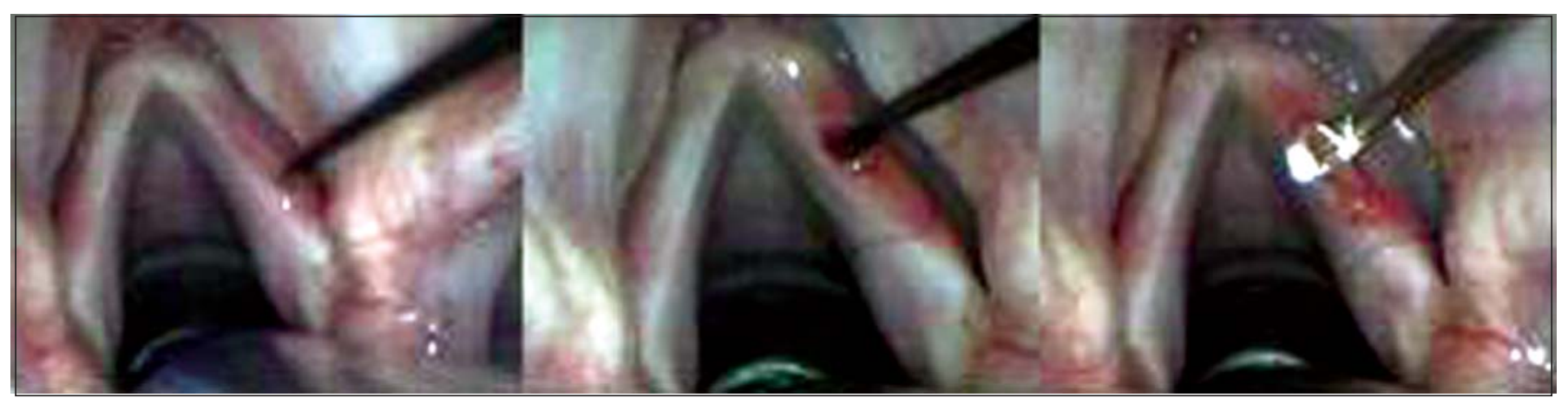

Figure 2. Incision on the upper surface of the vocal fold, 2 millimeters laterally to the first incision and detachment under the region delimited by two incisions.

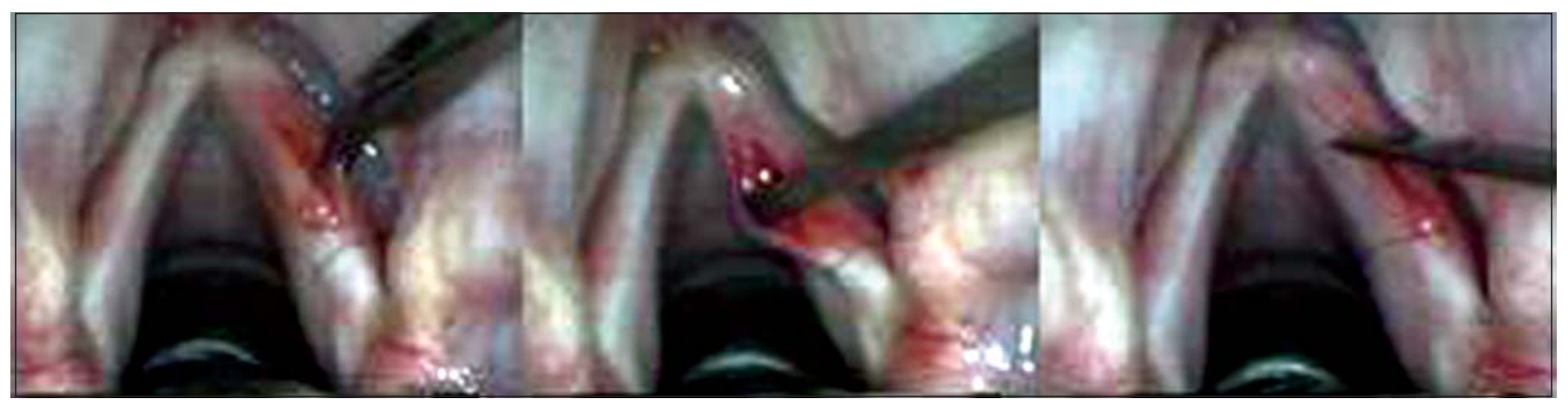

Figure 3. Performance of pediculated graft, positioning on subepithelial region and fixation with fibrin glue.

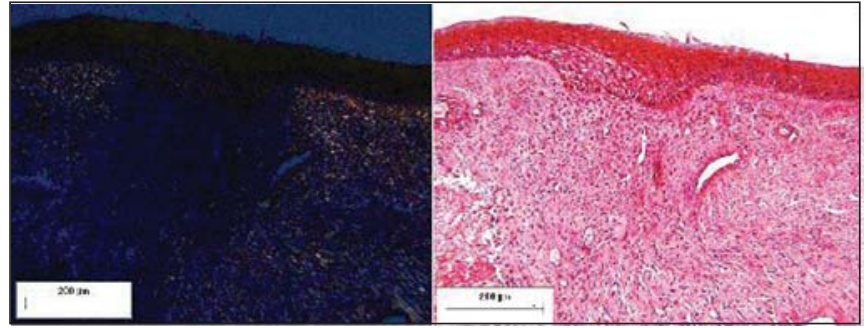

Figure 4. Pediculated flap placed on the submucous bed of the tested dog (postoperative day 10). Staining: Syrius Red under polarized light and HE.

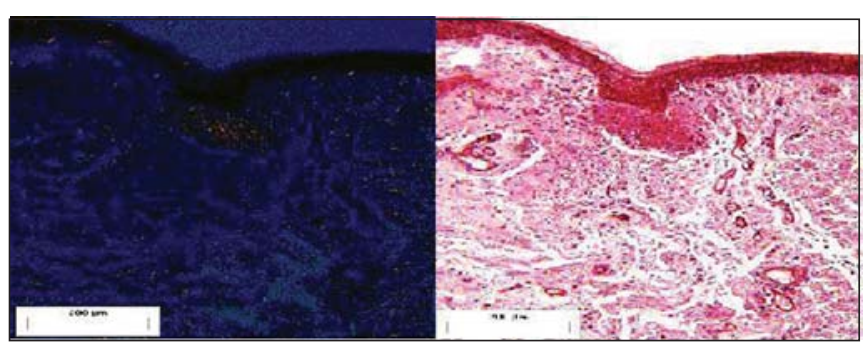

Figure 5. Pediculated flap placed on the submucous bed of the tested dog (postoperative day 30). Staining: Syrius Red under polarized light and $\mathrm{HE}$. 
images were digitalized through the camera Nikon DXM 1200 (Nikon, Melville, New York) and transferred to the computer Pentium IV, using the application Image Pro-Plus version 4.5.1.22 for Windows Media Cybernetics.

After histological preparation, we had the slides stained with Syrius Red and HE of 3 studied vocal folds in 5 different postoperative periods, plus 15 control vocal folds. The values of total, type I and type III collagen and the number of cell nuclei in each tested group with 3 dogs corresponding to postoperative days 10, 30, 90, 180 and 360 were descriptively and analytically studied. Mean and standard deviation measures were used to describe the sample. To compare the studied groups with the control group, we used U test by Wilcoxon-Mann-Whitney to analyze small samples, defining $D=0.05$ as the parameter for null hypothesis.

\section{RESULTS}

On the slides corresponding to 10 postoperative day in the tested group, pediculated flap could be identified in the area corresponding to lamina propria superficial region. After this period, only the area of the pedicle could be identified on day $30(3 / 3)$, day $90(2 / 3)$, day $180(2 / 3)$ and day $360(2 / 3)$. Total collagen area measured in the 15 vocal folds in the tested group ranged from $688.58 \mathrm{~m}^{2}$ to 4097.22 $\mathrm{P}^{2}$; standard deviation of 1155.31 and median of $1715.62 \mathrm{P}^{2}$; in the control group, the area ranged from $1002.21 \mathrm{P}^{2}$ to $3395.33 \mathrm{P}^{2}$, with standard deviation of 734.33 and median of $2054.87 \mathrm{P}^{2}$. Type III collagen area in the 15 vocal folds of the studied group ranged from $58.05 \mathrm{P}^{2}$ to 1479.38 $\mathrm{P}^{2}$, standard deviation of 241.98 and median of $261.62 \mathrm{~m}^{2}$; the area of the control group ranged from $58.27 \mathrm{P}^{2}$ to $1028.38 \mathrm{P}^{2}$, standard deviation of 248.48 and median of $475.94 \mathrm{P}^{2}$.

Type I collagen area in the tested group ranged from 595.17 $\mathrm{P}^{2}$ to $3958.30 \mathrm{P}^{2}$, the standard deviation was 1229.64 and median was $1113.28 \mathrm{P}^{2}$; the area of the control group ranged from $286.23 \mathrm{P}^{2}$ to $2695.80 \mathrm{P}^{2}$, standard deviation was 1229.64 and median was $1491.46 \mathrm{P}^{2}$.

The number of cell nuclei in the tested groups ranged from 21 to 79 nuclei, standard deviation of 17.51 and median 39. In the control group, the variation of nuclei was 8 to 89 , standard deviation of 23.88 and median of 27.

The variation of total and type I collagen during the period of observation suggested a tendency of increase in tested groups on days 90 and 180 after the surgery, followed by drop on day 360 (Graph 1, Tables 1 and 2). On postoperative day 30 , means of total and type I collagen in the studied group were below what we had for the control group (Tables 1 and 2). However, in the analyzed subgroups $(n=3)$, concerning total and type I collagen, only those values related to day 180 presented statistically significant difference $(p<0.05)$ compared to the control group $(n=15)$ after application of Wilcoxon-Mann-Whitney U test.

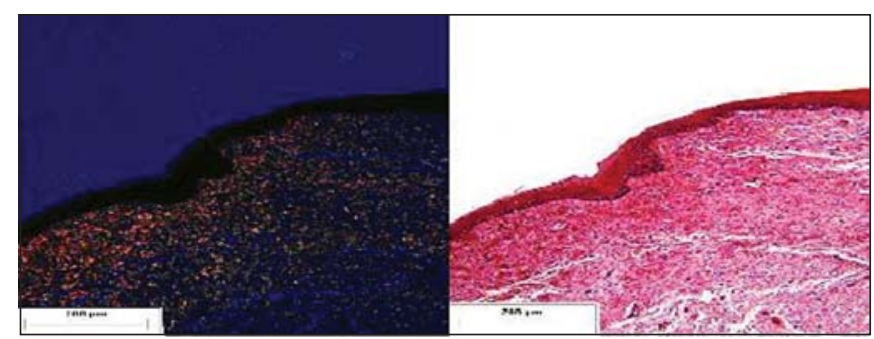

Figure 6. Pediculated flap placed on the submucous bed of the tested dog (postoperative month 12). Staining: Syrius Red under polarized light and HE.

Means of type III collagen area in the studied groups were always lower than those in the collagen groups (Graph 1) and reached levels below those of the control group (Tables 1 and 2) during the whole period of observation. Considering the postoperative period, only day 180 presented statistically significant reduced values $(\mathrm{p}<0.05)$.

There was no statistically significant correlation in the different periods of postoperative observation concerning number of nuclei on the lamina propria surface layer between the tested and control groups. There was only an initial increase on the average of number of nuclei in the studied group on day 10 PO (postoperative), followed by drop after this period (Tables 1 and 2).

\section{DISCUSSION}

Authors such as Duke and Shaw considered that there is still no ideal implantable substance to apply on the lamina propria of vocal folds ${ }^{18,19}$. In the studies carried out by Mikus et $a .^{20}$, we confirmed that there has been a very heterogeneous absorption of fat, causing variation between $2.3 \%$ and $70 \%$, in addition to worsening of vocal quality within 3 to 6 months after the surgery. Duke et al. ${ }^{18}$ suggested the feasibility of fascia graft up to one year. However, postoperative results can be influenced by early extrusion or absorption. Courey ${ }^{12}$ suggested that the implantation of collagen on the lamina propria superficial layer has potential effects concerning local reduction of viscosity.

The flap developed by the present technique followed the vascular pathways parallel to the free margin. Analyses made by Bardach ${ }^{21}$ defined that for the feasibility of a skin flap it is required to have a flow of about 1 to $2 \mathrm{ml}$ per minute for $100 \mathrm{cc}$ of tissue. The proposed flap in our study required $0.004 \mathrm{ml} /$ minute. Therefore, this measure was not made.

The observation of the chronological distribution of total and type I collagen in the studied group suggested an increase in its levels on days 90 and 180 PO, but there was statistically significant difference only on day 180 . Rosseau and Thibeault ${ }^{22,23}$ studied the scarring process of lamina propria and noticed that pro-collagen was more present in 
the 2nd month postoperative, with stabilization of levels in the 6th month, the same period in which there were higher density collagen fibers manifested on the surgical wound.

After 180 PO day, there was reduction on the mean of total and type I collagen, with similar levels to the control group. Few experimental studies of the larynx are extended for more than 6 months, but further studies are required to reach better conclusions about longer periods of observation.

The comparison of measurements obtained in the group that received the pediculated flap with the two studied groups from Cervantes et al. ${ }^{24}$ is suggestive of the fact that the present study had lower levels of total collagen on day 30 PO. This piece of data may be comparable with less local fibrosis, but, owing to the reduced number of dogs tested in the present study $(n=3)$, nothing could be confirmed.

The mean area of type III collagen in the tested group was below that of the control group, but there was statistically significant difference only on day 180 PO.

Table 1. Total, type III and type I collagen and number of cell nuclei. Calculation of the mean of each postoperative period.

\begin{tabular}{|c|c|c|c|c|c|}
\hline & & \multicolumn{3}{|c|}{ Collagen $\left(\mathrm{P}^{2}\right)$} & \multirow{2}{*}{$\begin{array}{c}\text { Cell } \\
\text { Nuclei }\end{array}$} \\
\hline & & Total & Type III & Type I & \\
\hline & DOG 1 & 3907,85 & 83,44 & 3824,41 & 44 \\
\hline 10 & DOG 2 & 688,58 & 93,4 & 595,18 & 79 \\
\hline \multirow[t]{3}{*}{ DPO } & DOG 3 & 1330,73 & 718,78 & 611,95 & 51 \\
\hline & MD 10 DAYS & 1975,72 & 298,53 & 1677,18 & 58 \\
\hline & DOG 4 & 1741,01 & 58,05 & 1682,96 & 53 \\
\hline 30 & DOG 5 & 1348,96 & 478,29 & 870,67 & 24 \\
\hline \multirow[t]{3}{*}{ DPO } & DOG 6 & 2396,14 & 591,93 & 1804,21 & 36 \\
\hline & MD 30 DAYS & 1828,7 & 376,09 & 1452,61 & 38 \\
\hline & DOG 7 & 1715,62 & 602,34 & 1113,29 & 64 \\
\hline 90 & DOG 8 & 1027,49 & 82,77 & 944,72 & 21 \\
\hline \multirow[t]{3}{*}{ DPO } & DOG 9 & 3794,55 & 294,4 & 3500,15 & 29 \\
\hline & MD 90 DAYS & 2179,22 & 326,5 & 1852,72 & 38 \\
\hline & DOG 10 & 4097,22 & 138,92 & 3958,3 & 29 \\
\hline 180 & DOG 11 & 3303,84 & 136,69 & 3167,16 & 47 \\
\hline \multirow[t]{3}{*}{ DPO } & $\mathrm{DOG}$ & 2590,43 & 335,9 & 2254,54 & 27 \\
\hline & MD 180 DAYS & 3330,49 & 203,83 & 3126,66 & 34 \\
\hline & DOG 13 & 1080,18 & 261,63 & 818,55 & 21 \\
\hline 360 & DOG 14 & 1214,96 & 124,94 & 1090,02 & 39 \\
\hline \multirow[t]{2}{*}{ DPO } & DOG 15 & 1479,39 & 696,52 & 782,87 & 62 \\
\hline & MD 360 DAYS & 1258,17 & 361,02 & 897,15 & 41 \\
\hline
\end{tabular}

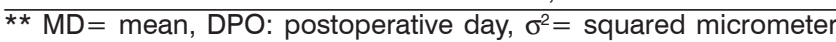

Table 2. Area of total, Type III and Type I collagen and number of cell nuclei in the control group. Calculation of mean and median.

\begin{tabular}{|c|c|c|c|c|}
\hline & \multicolumn{3}{|c|}{ Collagen (m2) } & \multirow{2}{*}{$\begin{array}{c}\text { Cell } \\
\text { Nuclei }\end{array}$} \\
\hline & Total & Type III & Type I & \\
\hline DOG 1 & 2187,31 & 58,28 & 2129,04 & 15 \\
\hline DOG 2 & 2151,52 & 660,05 & 1491,47 & 27 \\
\hline DOG 3 & 1407,8 & 394,73 & 1013,06 & 20 \\
\hline DOG 4 & 1932,06 & 368,22 & 1563,84 & 8 \\
\hline DOG 5 & 3395,34 & 699,54 & 2695,8 & 18 \\
\hline DOG 6 & 2532,83 & 657,59 & 1875,24 & 52 \\
\hline DOG 7 & 2054,88 & 843,72 & 1211,16 & 13 \\
\hline DOG 8 & 1002,21 & 463,19 & 539,03 & 15 \\
\hline DOG 9 & 1890,67 & 609,38 & 1281,29 & 69 \\
\hline DOG 10 & 2301,4 & 432,88 & 1868,53 & 28 \\
\hline DOG 11 & 2027,92 & 774,03 & 1253,89 & 35 \\
\hline DOG 12 & 2469,86 & 475,94 & 1993,92 & 63 \\
\hline DOG 13 & 828,28 & 363,75 & 464,53 & 43 \\
\hline DOG 14 & 834,32 & 248,09 & 286,24 & 23 \\
\hline DOG 15 & 2922,42 & 1028,39 & 1894,03 & 89 \\
\hline MEAN & 1995,92 & 538,52 & 1437,4 & 34,5 \\
\hline MEDIAN & 2054,87 & 475,94 & 1491,46 & 27 \\
\hline
\end{tabular}

$\mathrm{MD}=$ mean, $\mathrm{P}^{2}=$ squared micrometer 


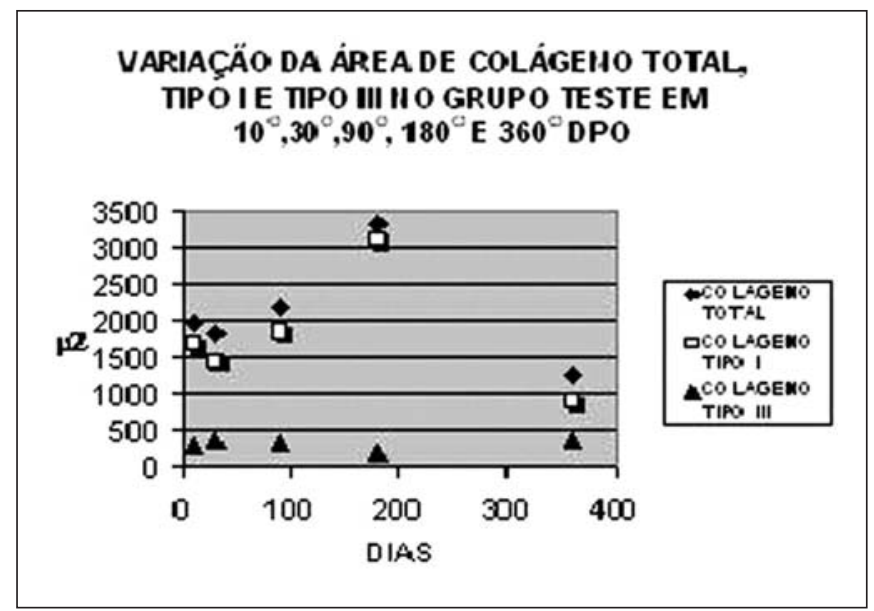

Graph 1. Variation of mean area of total, Type I and Type III collagen in postoperative period ( $n=3$ for each period of observation).

Findings related to analysis of type III collagen differ partially from other studies ${ }^{22,23}$, which noted that pro-collagen (immature form of collagen) was maintained at higher levels than those measured in the control group up to month 2 , in addition to the fact that in month 6 there was simultaneous decrease of pro-collagen and increase of more dense collagen.

The analysis of extracellular matrix behavior after application of surgical technique of pediculated flap revealed that there were significant changes concerning the increase in the area of more dense collagen (type I), associated with reduction in the area of immature or less dense collagen (type III) on day 180 PO. It may suggest similarities with postoperative findings of other experimental studies in the larynx, except for persistent low levels of Type III collagen during the period of observation.

More comprehensive studies are required, comprising a control group in which a simple incision is made and with the use of specific antibodies to identify different subtypes of collagen fibers, elastic fibers, fibronectin, hyaluronic acid, other aminoglycan, proteoglycan, lipids and carbohydrates are necessary to better understand the impact of pediculated flaps on the lamina propria superficial layer.

The means of number of nuclei in the tested groups reached high levels on 10 day $\mathrm{PO}$, progressing for the decrease after day 30 . These may be data compatible with the scarring process on the transition of proliferative phase to the remodeling phase ${ }^{25}$, however, we did not find statistically significant results in any of the observed periods.

Postoperative observations made under contact laryngoscope did not detect the onset of compatible lesions with vocal cysts, as well as significant affections in vascularity of the site where the flap was positioned. It is worth reporting that the present study was performed in dogs and their lamina propria has more percentage collagen than human lamina propria, especially on the superficial layer ${ }^{17}$. The analysis of collagen, therefore, can be more accurate for the regeneration in dogs than in men.

The present study was unheard-of concerning the prolonged time of postoperative observation in dogs (10 days to 1 year) and concerning the introduction of a new surgical technique. Some issues could not be completely answered with the results obtained, but they also gave rise to new perspectives, looking for checking complete and complex responses.

\section{CONCLUSIONS}

The study showed that in the group of dogs in which the technique of vocal fold pediculated flap was applied there was tendency to increase the levels of total and type I collagen on the lamina propria surface layer on days 90 and $180 \mathrm{PO}$, followed by drop on day 360; however, statistically significant difference was found only on day 180 $\mathrm{PO}$.

The mean of type III collagen in the studied group was below that of the control group in all periods of observation; however, there was statistically significant difference on day 180 PO.

The number of cell nuclei in the tested group was higher on day $10 \mathrm{PO}$, followed by reduction on levels after day 30 , but we did not find statistically significant results in any of the observed periods.

\section{REFERENCES}

1. Ishiki N, Tsuji DH, Sennes U. Tireoplastia. 1a edição. São Paulo: Bios Comunicação e Editora Ltda.; 1999. 1-49.

2. Ford CN. Advances and Refinements in Phonosurgery. Laryngoscope 1999; 109: 1891-900.

3. Fisher KV, Telser A, Phillips JE, Yeates DB. Regulation of vocal fold transepithelial water fluxes. J Appl Physiol 2001; 91: 140111.

4. Junqueira LCU, Montes GS, Martins JEC. Dermal Collagen Distribution. A Histochemical and Ultrastructural Study. Histochemistry 1983; 79: 397-403.

5. Benninger MS, Alessi D, Archer S, Bastian R, Ford C, Koufman J, Sataloff RT, Spiegel JR, Woo P. Vocal fold scarring: current concepts and management. Otolaryngology- Head and Neck Surgery 1996; 115(5): 474-82.

6. Ford CN, Inagi K, Khidr A, Bless, DM, Gilchrist KW. Sulcus vocalis: a rational analytical approach to diagnosis and management. Ann Otol Rhinol Laryngol 1996; 105: 189-200.

7. Hirano M, Tanaka S, Yoshida T, Hibi S. Sulcus vocalis: functional aspects. Ann Otol Rhinol Laryngol 1990; 99: 679-83.

8. Saccogna PW, Werning JW, Setrakian S, Strauss M. Lipoinjection in the paralyzed feline vocal fold: Study of graft survival. Otolaryngology-Head and Neck Surgery 1997; 117(5): 465-70.

9. Woo P, Rahbar R, Wang Z. Fat implantation into reinke space a histologic and stroboscopic study in the canine. Ann Otol Rhinol Laryngol 2000; 109: 77-85. 
10. Tsunoda K, Takanosawa M, Niimi S. Autologous transplantation of fascia into the vocal fold: a new phonosurgical technique for glotal incompetence. Laryngoscope 1999; 109: 504-8.

11. Courey MS. Homologous Collagen Substances for Vocal Fold Augmentation. Laryngoscope 2001; 111: 747-58.

12. Kriesel KJ, Thibeault SL, Chan RW, Suzuki T, Vangroll PJ, Bless DM, Ford DB, Ford CN. Treatment of vocal fold scarring: rheological and histological measures of homologous collagen matrix. Ann Otol Rhinol Laryngol 2002; 111: 884-8.

13. Pontes P, Behlau M. Treatment of sulcus vocalis: auditory perceptual and acoustical analysis of the slicing mucosa surgical technique. J Voice 1993; 7(4): 365-76.

14. Gray S, Thibeault S, Tresco P. Witnessing a revolution in voice research: genomics, tissue engineering, biochips and what's next! Logoped Phoniatr Vocol 2003; 28(1): 7-13.

15. Glatz FR, Kalkanis J, Neumeister M, Suchy H, Lyons S, Mowlawi A. Volume analysis of preadipocyte injection for vocal cord medialization. Laryngoscope 2003; 113(7): 1113-7.

16. Grellet M, Carneiro CG, Aguiar LN, Rosa MO, Pereira JC. Técnica do retalho pediculado para correção do sulco vocal. Revista Brasileira de Otorrinolaringologia 2002; 68(1): 75-9.

17. Sweat F, Pucchtler H, Rosenthal ASI. Sirius Red F3BA as a Stain for Connective Tissue. Archives of Pathology 1964; 78: 69-72.

18. Duke SG, Salomon J, Blalock D, Postma GN. Fascia augmentation of the vocal fold: graft yield in the canine and preliminary clinical experience. Laryngoscope 2001; 111: 759-64.
19. Shaw GY, Szewczyk MA, Searle J, Woodroof J. Autologous fat injection into the vocal folds: technical considerations and long-term follow-up. Laryngoscope 1997; 107: 177-86.

20. Mikus JL, Koufman JA, Kilpatrick SE. Fate of liposuctioned and purified autologous fat injections in the canine vocal fold. Laryngoscope 1995; 105: 17-22.

21. Bardach J, Voots RJ, McCabe BF, Hsu MM. Photoplethysmography in the prediction of experimental flap survival. Ann Otol Rhinol Laryngol 1979; 88(5Pt1): 673-41.

22. Rousseau B, Hirano S, Scheidt TD, Welham NV, Thibeault SL, Chan RW, Bless DM. Characterization of vocal fold scarring in a canine model. Laryngoscope 2003; 113: 620-7.

23. Thibeault SL, Gray SD, Li W, Chen Z. Instability of extracellular matrix gene expression in primary cell culture of fibroblasts from human vocal fold lamina propria and tracheal scar. Ann Otol Rhinol Laryngol 2002; 111: 8-14.

24. Cervantes FCC. Estudo comparativo Histológico na Prega Vocal após incisão com instrumental a Frio e a Laser de $\mathrm{CO}_{2}$ em Modelo Animal. Dissertação de Mestrado. Faculdade de Medicina de Ribeirão Preto; 2003.

25. Goffi FS. Técnica cirúrgica: Bases anatômicas, fisiopatológicas e técnicas da cirurgia, 4⿳亠丷a . Edição. Rio de Janeiro: Editora Atheneu; 2001; 285-95. 